* Presenting author

\title{
0001 DEMOGRAPHIC RISK FACTORS OF SELF-IMMOLATION
}

A Ahmadi, R Mohammadi, D C Schwebel, H Khazaie, N Yeganeh, A Almasi, I Kassani* Correspondence: Kermanshah University of Medical Sciences, Imam Reza Hospital, Kerman, Iran

10.1136/ip.2010.029215.1

Objective To investigate demographic risk factors for selfimmolation patients.

Methods In a case-control study, 30 consecutive cases of deliberate self-inflicted burns admitted to the regional Burn centre (Imam Khomeini hospital in Kermanshah province, Iran) were compared with 30 controls who were selected from the community and matched by gender, age and living area. All cases and controls were reviewed for demographic variables, including: age, gender, living area, family size, marital status, bearing and number of children, body mass index (BMI), birth order, employment state, educational status, early school drop-out and parent/guardian employment status.

Results Two variables emerged as related to risk of selfimmolation. Being the first or last child in family birth order was associated with increased risk of self-immolation. Moreover, among the married participants, having children was associated with decreased risk of self-immolation. The comparisons of other variables were not statistically significant. In multivariate analyses, none of the variables predicted risk for self-immolation.

Conclusion This study suggests that being the first or last child of a family might be a risk factor for self-immolation. For married persons, having children might serve as a protective factor from self-immolation. Other variables such as family size, marital status, number of children, BMI, employment state, educational status, early school drop-out and parent/ guardian employment status did not play a role as individually protective or risk factors for self-immolation. 